\title{
Tweens are not teens: the problem of amalgamating broad age groups when making pandemic recommendations
}

\author{
Brae Anne McArthur ${ }^{1,2} \cdot$ Sheri Madigan ${ }^{1,2} \cdot$ Daphne J. Korczak $^{3,4} \mathbb{C}$
}

Received: 17 February 2021 / Accepted: 6 October 2021 / Published online: 29 October 2021

(c) The Author(s), under exclusive licence to The Canadian Public Health Association 2021

\begin{abstract}
Demarcating childhood into two distinct and broad 10-year age bands of over and under age 10 is a disservice to our tween population (9-12 years), and may be overlooking our role in understanding the negative impacts of SARS-CoV-2 (COVID19) during a formative period of development. In this commentary, we discuss the importance of considering tweens as a unique population of youth who are differentially impacted by the COVID-19 pandemic. We first describe the distinctive progress of tweens across various facets of developmental health, followed by recommendations to improve understanding and address impact of the pandemic and its restrictions on tweens. The COVID-19 pandemic has had a large impact on the day-to-day lives of tweens and what we do now will have long-lasting effects on their lifelong trajectories.
\end{abstract}

\section{Résumé}

La séparation de l'enfance en deux groupes d'âge distincts (moins de 10 ans, 10 ans et plus) ne nous permet pas de bien caractériser les effets négatifs du SRAS-Cov-2 (COVID-19) chez les préadolescents (âgés entre 9 et 12 ans), ceux-ci étant dans une phase spécifique de leur développement. Dans cet commentaire, nous discutons de l'importance de considérer les préadolescents comme une population unique lorsqu'il s'agit de déterminer comment ils sont affectés par la pandémie du COVID-19. Nous décrivons d'abord les progrès uniques aux préadolescents dans diverses facettes de leur développement, suivis par des recommandations pour améliorer la compréhension de l'impact de la pandémie et de ses restrictions sur les préadolescents. La pandémie du COVID-19 a changé drastiquement la vie quotidienne des préadolescents, et les considérer comme un groupe unique de l'enfance aura des effets considérables sur notre habileté de les aider durant le reste de leur développement.

Keywords Tweens $\cdot$ COVID-19 $\cdot$ Public health $\cdot$ Pre-adolescence

Mots-clés Préadolescents $\cdot$ COVID-19 $\cdot$ santé publique $\cdot$ préadolescence

While SARS-CoV-2 (COVID-19) is not a severe health risk to the vast majority of children (Castagnoli et al., 2020), our

Daphne J. Korczak

daphne.korczak@sickkids.ca

1 Department of Psychology, Faculty of Arts, University of Calgary, Calgary, AB, Canada

2 Alberta Children's Hospital Research Institute, Alberta Children's Hospital, Calgary, AB, Canada

3 Department of Psychiatry, Hospital for Sick Children, 1145 Burton Wing, 555 University Avenue, Toronto, ON M5G 1X8, Canada

4 Department of Psychiatry, Faculty of Medicine, University of Toronto, Toronto, ON, Canada public health response to it is. Subjected to strict stay-athome orders, children and adolescents have suffered from negative impacts on mental health, well-being, and educational attainment, which are only beginning to be quantified (Christakis, 2020; Cost et al., 2021; Hafstead et al., 2021). As countries refine public health measures in response to fluctuations in community prevalence rates of COVID-19, preventive measures have generally been implemented using the World Health Organization (WHO) definition of adolescence (10 to 19 years; World Health Organization, 2020), considering children as either under or over age 10, without much thought, or transmission data, to support (Kim et al., 2020) the consequences of these arbitrary groupings. Although it may be statistically easier to amalgamate older 
tweens (i.e., 10-13 years, or middle schoolers) with teens (i.e., 14-19 years, or high schoolers) and to consider 10-year age bands when interpreting COVID-19 data and recommendations, within Western contexts tweens (ages 9-12) represent a unique population of youth who are differentially impacted by the COVID-19 pandemic. Categorizing adolescents as individuals aged 10-19 years both medically and developmentally overlooks and underserves "tweens," who represent a particularly distinct population during this pandemic. Below we present the distinctive progress of tweens across various facets of developmental health, followed by recommendations to improve understanding and address the impact of the pandemic and its restrictions on tweens.

\section{Brain and cognitive development}

Compared with the childhood (under 9 years) or teen years (13-19 years), the tween stage is notable for its unique developmental changes. During the tween years, the brain undergoes extensive remodeling and activation of subcortical structures, a peak in grey matter volume, maturation of axonal connections, and synaptic reductions and consolidations (Del Giudice, 2014). In fact, the tween period is second only to infancy in terms of the magnitude of developmental changes in the brain (Knudsen, 2004; Sharma et al., 2013). Due to these substantial neurodevelopmental changes, the tween period involves increases in reasoning and problemsolving skills, self-regulation and executive functions (i.e., attention, inhibition, planning), sense of gender identity, as well as the onset of sexual and romantic attractions, and overall more complex social and moral reasoning (e.g., the ability to hold and consider multiple perspectives and conflicting views, and to understand stereotypes and social hierarchies; Dahl et al., 2018; Del Giudice, 2014). As such, the tween years represent a "sensitive period" (Knudsen, 2004) in which youth have the best chance of reaching their full potential when they are exposed to stimulating environments, learning experiences, and social interactions that promote and strengthen their capabilities. However, in many countries, their age requires that they have continued supervision at home, and thus, decisions regarding school closures and other COVID-19 recommendations should distinguish children and tweens, from teens, when deciding if activities (i.e., online programming) can occur in the absence of parental supervision.

The COVID-19 pandemic has resulted in significant changes to the daily activities and growth opportunities for tweens via school closures, social distancing from peers and other supports (e.g., teachers, coaches), home confinement, and online instruction, all examples of environmental, learning, and social experiences that may adversely impact how tweens come to view, interact with, experience, and contribute to the world and our society lifelong.

\section{Peer relationships}

The tween years springboard a child into the transition from exclusive dependence on family to one of increased autonomy. Peer interactions take on more primacy for tweens when compared with children (Schonert-Reichl, 2011), and youth place increasing emphasis on social affiliations and acceptance. Research supports that tweens direct a high level of psychosocial attention toward peer relationships, whereas older adolescents tend to shift their focus to matters of identity development (Collins \& Steinberg, 2006). Thus, peer relations during the tween period are crucial for developmental health (Prinstein \& Giletta, 2016).

Due to the current COVID-19 recommendations, tweens have lost valuable resources to develop and maintain social interactions (Brooks et al., 2020). As public health prevention strategies have refrained from considering developmental stage, many COVID-19 mitigation strategies have treated tweens similarly to teens, and in some cases, even similarly to adults. For the tween age range, re-opening measures have included: wearing a mask at school and in most social situations, physical distancing, online school models, and limited or no sport and extracurricular activities. These strategies are particularly harmful to tweens who are developmentally tasked with establishing the foundations of their peer networks. Having limited in-person contact with peers, and physical distancing when in contact, poses a challenge for building new relationships. Indeed, research during the COVID-19 pandemic is beginning to show the detrimental impact of the COVID-19 public health mitigation strategies on youth outcomes (Magson et al., 2021).

Without in-person contact, there is a reliance on virtual peer connections that are independent of parent supervision, but that tweens may not yet be able to navigate from a social, cognitive, or safety perspective. This premature increase in online exposure may lead to miscommunication with peers, feelings of exclusion, online solicitation, bullying, and increased social isolation as children in this age group are both vulnerable to social criticism (Diliberti et al., 2019; Kowalski \& Limber, 2007; Westenberg et al., 2007) and immature with respect to development of the adaptive defense mechanisms that are needed to buffer online rebukes or requests (Madigan et al., 2018). Additionally, recent research has shown that online social interactions are distinct from face-to-face or in-person interactions with peers (Nesi et al., 2020) and likely are not meeting the needs of tweens during this developmental stage. Since tweens are developmentally tasked with developing new peer networks (Collins \& Steinberg, 2006; Schonert-Reichl, 2011), in many 
cases, they may not have an established friendship network to transfer to online interactions.

\section{Physical activity, sleep, and screen time}

Another important developmental task during the tween years is establishing healthy lifestyle habits, such as physical activity, sleep, and screen use. Research confirms a decline in physical activity, increased sleep difficulties, and greater screen use as youth enter the teen years (Keyes et al., 2015; Rideout, 2015; Sallis, 2000). Healthy habits during the tween years are instrumental for mental health and wellbeing as tweens move into adolescence.

Although designed to slow the rate of infection, many of the strategies used to manage COVID-19 are forcing tweens to stay indoors, resulting in increased sedentary time (McArthur et al., 2021), a reduction in structured activities (e.g., sports; Elliott et al., 2021), and disrupted sleep routines (Ramos Socarras et al., 2021), all of which can have a negative effect on health patterns lifelong. These disruptions pose a unique problem for tweens who are less responsive to their parents' directions of their daily activities, unlike younger children. Furthermore, compared with teens, tweens are still developing the insight and executive functioning required to appreciate the importance of healthy behaviours and implement these activities in their lives independently. With the implementation of COVID-19 prevention measures comes a clear need to consider the risk-to-benefit ratio for this particular age group.

\section{Mental health}

Arguably the most important reason to consider tweens as a unique population differentially impacted by the COVID-19 pandemic is the strong evidence that it is in this developmental period where we see the most rapid rise in mental health disorder symptoms (Whiteford et al., 2013). Specifically, there is a rapid escalation of anxiety, depression, and child behaviour symptoms from ages 10 to 13 (Erskine et al., 2015), and suicide is now a leading cause of death for this age range (Statistics Canada, 2020).

It is no surprise that youth mental health difficulties have increased during COVID-19 (Racine et al., 2021), given that many of the stressors present during the pandemic (e.g., social isolation, family stress, cancellation of important milestones such as graduation) are predictors of deleterious mental health outcomes. The mental health vulnerability of tweens and its associated downstream consequences necessitate targeted recommendations and preventive measures for this developmental stage.

\section{What can we do to help tweens during the pandemic?}

A growing appreciation of the distinctive neurodevelopmental, social, health, behavioural, and mental health factors associated with the tween years is at odds with our current pandemic-related recommendations related to the COVID19 pandemic. Demarcating childhood into two broad 10-year age bands of over and under age 10 is a disservice to our tween population, and may be overlooking our role in understanding the negative impacts of COVID-19 during a formative period of development.

We propose the following recommendations to improve our understanding and strategy to address the impact of pandemic restrictions on tweens: First, we recommend reporting COVID-19 prevalence and transmission data in developmentally appropriate age bands to distinguish 9-12year olds from 13-19-year olds. Few sources have taken this approach, and data are needed to support and inform tailored recommendations for tweens. Second, we suggest examining the impact of public health prevention strategies by developmental stage. Applying a developmental lens to the interpretation and understanding of public health recommendations will allow a more informed method of assessing risks and benefits of mitigation strategies to direct future decision-making. Last, we recommend providing targeted resources for tweens when lifting or re-instating mitigation strategies. From a cost-benefit analysis, investing now in our tweens' health—mental and physical—can result in a substantial return on investment in the long term (Heckman, 2006), and may help moderate some of the expected adverse outcomes for this age range.

The COVID-19 pandemic has had a large impact on the day-to-day lives of tweens. As we continue to manage and recover from this crisis, we need to consider tweens as a unique population differentially impacted by the choices we make and the strategies we use today. What we do now will have long-lasting impacts on the lifelong trajectories of these youth.

Author contributions All authors contributed to the conception and drafting of this commentary. All authors read and approved the final version.

Data availability N/A.

Code availability N/A.

\section{Declarations}

Ethics approval N/A.

Consent to participate N/A. 
Consent for publication N/A.

Conflict of interest The authors declare no competing interests.

\section{References}

Brooks, S. K., Webster, R. K., Smith, L. E., Woodland, L., Wessely, S., Greenberg, N., \& Rubin, G. J. (2020). The psychological impact of quarantine and how to reduce it: A rapid review of the evidence. Lancet, 395, 912-920. https://doi.org/10.1016/S0140-6736(20)30460-8

Castagnoli, R., Votto, M., Licari, A., Brambilla, I., Bruno, R., Perlini, S., \& Marseglia, G. L. (2020). Severe acute respiratory syndrome coronavirus 2 (SARS-CoV-2) infection in children and adolescents: A systematic review. JAMA Pediatrics, 174(9), 882-889. https://doi.org/10.1001/jamapediatrics.2020.1467

Christakis, D. A. (2020). Pediatrics and COVID-19. JAMA, 324(12), 1147. https://doi.org/10.1001/jama.2020.14297

Collins, W. A., \& Steinberg, L. (2006). Adolescent development in interpersonal context. In W. Damon, R. Lerner, \& N. Eisenberg (Eds.), Handbook of child psychology: Vol 3 Social, emotional, and personality development (6th ed). Wiley.

Cost, K. T., Crosbie, J., Anagnostou, E., Birken C. S., Charach, A., Monga, S., Kelley, E., Nicolson, R., Maguire, J. L., Burton, C. L., Schachar, R. J., Arnold, P. D., \& Korczak, D. J. (2021). Mostly worse, occasionally better: Impact of COVID-19 pandemic on the mental health of Canadian children and adolescents. European Child and Adolescent Psychiatry. https://doi.org/10.1007/s00787-021-01744-3

Dahl, R. E., Allen, N. B., Wilbrecht, L., \& Suleiman, A. B. (2018). Importance of investing in adolescence from a developmental science perspective. Nature, 554(7693), 441-450. https://doi.org/10. 1038/nature25770

Del Giudice, M. (2014). Middle childhood: An evolutionary-developmental synthesis. Child Development Perspectives, 8(4), 193-200. https://doi.org/10.1111/cdep.12084

Diliberti, M., Jackson, M., Correa, S., Padgett, Z., \& US Department of Education. (2019). Crime, Violence, Discipline, and Safety in U.S. Public Schools: Findings from the School Survey on Crime and Safety: 2017-18 (NCES 2019-061). National Center for Education Statistics.

Elliott, S., Drummond, M. J., Prichard, I., Eime, R., Drummond, C., \& Mason, R. (2021). Understanding the impact of COVID-19 on youth sport in Australia and consequences for future participation and retention. BMC Public Health, 21, 448. https://doi.org/10. 1186/s12889-021-10505-5

Erskine, H. E., Moffitt, T. E., Copeland, W. E., Costello, E. J., Ferrari, A. J., Patton, G., \& Scott, J. G. (2015). A heavy burden on young minds: The global burden of mental and substance use disorders in children and youth. Psychological Medicine, 45(7), 551-1563.

Hafstad, G. S., Saetren, S. S., Wentzel-Larsen, T., \& Augusti, E. (2021). Adolescents' symptoms of anxiety and depression before and during the COVID-19 outbreak - A prospective population-based study of teenagers in Norway. The Lancet Regional Health - Europe, 5, 100093. https://doi.org/10.1016/j.lanepe.2021.100093

Heckman, J. J. (2006). Skill formation and the economics of investing in disadvantaged children. Science, 312(5782), 1900-1902.

Keyes, K. M., Maslowsky, J., Hamilton, A., \& Schulenberg, J. (2015). The great sleep recession: Changes in sleep duration among US adolescents, 1991-2012. Pediatrics, 135(3), 460-468. https://doi. org/10.1542/peds.2014-2707

Knudsen, E. I. (2004). Sensitive periods in the development of the brain and behavior. Journal of Cognitive Neuroscience, 16(8), 1412-1425. https://doi.org/10.1162/0898929042304796

Kim, L., Whitaker, M., O'Halloran, A., Kambhampati, A., Shua J. Chai, Reingold, A., COVID-NET Surveillance Team. (2020).
Hospitalization rates and characteristics of children aged $<18$ years hospitalized with laboratory-confirmed COVID-19COVID-NET, 14 States, March 1-July 25, 2020. Retrieved from https://www.cdc.gov/mmwr/volumes/69/wr/mm6932e3.htm?s_ cid $=$ mm6932e3_w. Accessed $10 \mathrm{Jan} 2021$.

Kowalski, R. M., \& Limber, S. P. (2007). Electronic bullying among middle school students. Journal of Adolescent Health, 41(6 Suppl 1), S22-30.

Madigan, S., Villani, V., Azzopardi, C., Laut, D., Smith, T., Temple, J., \& Dimitropoulos, G. (2018). The prevalence of unwanted online sexual exposure and solicitation among youth: A meta-analysis. Journal of Adolescent Health, 63(2), 133-141.

Magson, N. R., Freeman, J. Y. A., Rapee, R. M., Richardson, C. E., Oar, E. L., \& Fardouly, J. (2021). Risk and protective factors for prospective changes in adolescent mental health during the COVID-19 pandemic. Journal of Youth Adolescnce, 50(1), 44-57. https://doi.org/10.1007/s10964-020-01332-9

McArthur, B., Racine, N., Browne, D., McDonald, S., Tough, S., \& Madigan, S. (2021). Screen time before and during COVID-19 in school aged children. Acta Pediatrica. https://doi.org/10.1111/ apa.15966

Nesi, J., Telzer, E. H., \& Prinstein, M. J. (2020). Adolescent development in the digital media context. Psychological Inquiry, 31(3), 229-234. https://doi.org/10.1080/1047840x.2020.1820219

Prinstein, M. J., \& Giletta, M. (2016). Peer relations and developmental psychopathology. Developmental psychopathology: Theory and method (3rd ed, Vol. 1, pp. 527-579). John Wiley \& Sons Inc.

Racine, N., McArthur, B., Cooke, J. E., Eirich, R., Zhu, J., \& Madigan, S. (2021). Global prevalence of depressive and anxiety symptoms in children and adolescents during COVID-19: A meta-analysis. JAMA Pediatrics. https://doi.org/10.1001/jamapediatrics.2021.2482

Ramos Socarras, L., Potvin, J., \& Forest, G. (2021). COVID-19 and sleep patterns in adolescents and young adults. Sleep Medicine, 83, 26-33. https://doi.org/10.1016/j.sleep.2021.04.010

Rideout, V. (2015). The Common Sense consensus: Media use by tweens and teens. Common Sense Media.

Sallis, J. F. (2000). Age-related decline in physical activity: A synthesis of human and animal studies. Medicine and Science in Sports and Exercise, 32(9), 1598-1600. https://doi.org/10.1097/00005 768-200009000-00012

Schonert-Reichl, K. A. (2011). Middle childhood inside and out: The psychological and social worlds of Canadian children ages 9-12, Full Report. University of British Columbia.

Sharma, S., Arain, Mathur, Rais, Nel, Sandhu, Johal. (2013). Maturation of the adolescent brain. Neuropsychiatric Disease and Treatment, 449https://doi.org/10.2147/ndt.s39776

Statistics Canada. (2020). Table 13-10-0392-01 Deaths and age-specific mortality rates, by selected grouped causes. Statistics Canada. https://doi.org/10.25318/1310039201-eng. Accessed 14 Oct 2020.

Westenberg, P. M., Gullone, E., Bokhorst, C. L., Heyne, D. A., \& King, N. J. (2007). Social evaluation fear in childhood and adolescence: Normative developmental course and continuity of individual differences. British Journal of Developmental Psychology, 25, 471-483. https://doi.org/10.1348/026151006X173099

Whiteford, H. A., Degenhardt, L., Rehm, J., Baxter, A. J., Ferrari, A. J., Erskine, H. E., \& Vos, T. (2013). Global burden of disease attributable to mental and substance use disorders: Findings from the Global Burden of Disease Study 2010. The Lancet, 382(9904), 1575-1586. https://doi.org/10.1016/s0140-6736(13)61611-6

World Health Organization. (2020). Adolescent Health. Retrieved from https://www.who.int/health-topics/adolescent-health/\#tab=tab_1. Accessed 10 Jan 2021.

Publisher's note Springer Nature remains neutral with regard to jurisdictional claims in published maps and institutional affiliations. 